\title{
THE EUROPEAN MODEL OF DEVELOPMENT FACED WITH THE QUATERNARY SECTOR EMERGENGE TEST
}

\author{
Dumitru Miron ${ }^{1 *}$, Dragoș Șeuleanu ${ }^{2}$, Cezar Radu Cojocariu ${ }^{3}$ \\ and Laura Benchea ${ }^{4}$ \\ 1) 3) 4) Bucharest University of Economic Studies, Bucharest, Romania \\ ${ }^{2)}$ ELI-NP, Magurele, Romania
}

Please cite this article as:

Miron, D., Șeuleanu, D., Cojocariu, C.R. and Benchea, L., 2019. The European Model of Development Faced with the Quaternary Sector Emergence Test. Amfiteatru Economic, 21(Special Issue No. 13), pp. 743-762.

\section{Article History}

Received: 22 August 2019

Revised: 2 September 2019

Accepted: 8 October 2019

DOI: $10.24818 / \mathrm{EA} / 2019 / \mathrm{S} 13 / 743$

\begin{abstract}
The European Union must identify and internalize the most acute challenges, prepare appropriate solutions to them, capitalize on its strengths, and avoid threats. The strategic philosophy can no longer be just rhetorical but must be found at the level of all European sectoral policies, national macroeconomic policies but also of the programs and projects launched by the actors operating in the business environment. The research is phenomenological in nature, with an emphasis on qualitative issues related to the most relevant paradigm changes at the level of European sectoral policies, national macroeconomic policies, as well as programs and projects launched by actors operating in the business environment. The topic that plays an important role in this research is the one related to the most appropriate structure of a modern economy, the emphasis being placed on the correlations and the causalities between them. The hypotheses from which it was started, the epistemological perspectives taken as the basis, the analytical drivers used, the research methodologies that were called upon but also the variables used took into account the change of the techno-industrial paradigm, the factors that influence the efficiency and sustainability of the new economic development models, the threats but also the opportunities that must be identified and encountered by those who decide at the macro, mezzo and microeconomic levels. The most important transformations that take place at the level of the macroeconomic and business development models were analyzed, updating them and offering some recommendations on how some systemic vulnerabilities can be treated. The paper ends by surprising the way in which Romania is positioned at the level of the switching process from an economy in which the primary and secondary sectors are prevalent to one in which the weight of the tertiary and quaternary sectors increases.
\end{abstract}

Keywords: new economic model; paradigm shift; quaternary sector; competitiveness; Romania.

JEL Classification : O40, O47, O52.

\footnotetext{
${ }^{*}$ Corresponding author, Dumitru Miron - dumitru.miron@ rei.ase.ro
} 


\section{Introduction}

One of the important topics dealt with by the economic research was that of the optimal structure of economies, the emphasis being placed on the correlations and causalities between them. The hypotheses from which most analysts started, the epistemological perspectives taken as a basis, the analytical drivers used, the research methodologies that were used, but also the variables used, led to the most interesting results. At European Union level, for several decades, there is no definitive answer to the question related to the type of development model that should be promoted, one focused on economic, social and territorial cohesion and other being focused on creating European poles of excellence in which the main driver should be increasing the level of external competitiveness. The possible alternative depends on a lot of parameters, both internal and external in nature, and becomes even more difficult to formalize as the European economy goes through a process of transition from the prevalence of the primary and secondary sectors to that of the tertiary and quaternary sectors. From the level of the Member States as well as from the Community bodies, the message must be transmitted that it is understood that a number of new challenges are exacerbated, the most pressing ones being: climate change, advancing the digitization process, "ageing" the population, some centrifugal trends in relation to the progressivity and the irreversibility of the European integration project, the short circuits emerging at the level of the multilateral trading system; the emergence of new global commercial actors. In these circumstances, both political and business decision-makers must accept that the switch from the position of "followers" to that of "leaders" will have to occur in a regional and international economic climate that is intended to be sustainable and generate economic rationality.

The fundamental transformations that occur at the level of the international geopolitical and geo-economic climate make absolutely pressing the subject of rethinking the package of techno-industrial paradigms. Understanding the true complexity and the special dynamics of the development models that can create added value for the current process of capitalization of the production factors invites the decision makers who act in the landscape of the new economy but also the experts from the academic and scientific environment to reflect dedicatedly on the fundamentals that have proved indisputable for a long time, to reconfigure the methodological architecture with which the system analyzes can be performed and to lean on a new set of questions to which other generation answers are required. Under the conditions of a new development model, aspects such as: deregulation of markets; trade liberalization; capital mobility; budgetary austerity; privatization of public utility networks; the transition from human capital to social or intellectual capital, will have significant meanings. In the new circumstances, which abound in what some specialists (Rodrick, 2019) call the " impossibility trilemmas", the "sometimes hidden" agendas of the main beneficiaries of the processes of globalization and regionalization, especially in the world, cannot be kept away. Particularly in the economic and social fields, the adverse effects of such an attitude can never be attractively packaged under the paradigm shift in technology.

The topic regarding the design of national economies, especially their sectoral component, was present in all the periods in which economic science dealt with it. A careful analysis of the literature allows to identify relevant concerns regarding the sustainability of the development models and the increase of prosperity they generate at Adam Smith, David Ricardo, Karl Marx, John Stuart Mill, but also the other contributors to the theory and 
economic practice. One of the constant epistemological challenges in which we tried to provide clarifying solutions was that of "material production", insisting on the delimitation between activities that can be considered productive and non-productive depending on the contribution made to the creation of tangible assets. A certain contribution to this analytical landscape was also made by Friedrich List (1841), who argued that "we need to consider certain important societal sectors such as education, public administration and the communications network as productive". One of the development models that made its career up to the early years of the 21st century is the 'Washington Consensus' and has held top positions on both global economic governance and national public policy agendas. An important contribution to the subject of how the standard structure of economies contributes to the economic growth was made by Colin Clark, who focused on the most relevant dynamic correlations existing between the primary, secondary and tertiary sectors. In the last decade of the twentieth century in the works dedicated to this topic, the interdisciplinary parameter was introduced, the attention of the researchers being shifted to the importance that the various sectors of the economy had at different times of the economic development, an even clearer delimitation between the productive activities. and the non-productive ones and the argumentation of the specificity of each of the stages of the growth process. Since the beginning of this century, some analysts (Harmaakorpi, Haikonenta and Kauranen, 2003) pointed out that in the specialized language several terms have been introduced that try to describe the interesting developments that occur in the cross-sectoral picture of modern economies. The authors of this article make several arguments in favor of the idea that the new economic model must synergistically integrate a quaternary sector in which the intangible assets are a priority and in which knowledge and creativity are the main factors of production.

\section{How important is the European Union's need for a new development model?}

In the document entitled "A new strategic agenda 2019-2024", the European Council outlined the strategic directions that must be considered by all the social actors acting at the level of the European economic picture, the most important being: "protecting citizens and fundamental freedoms; developing a strong and vibrant economic base; building a climateneutral, green, fair and social Europe; promoting Europe's interests and values on the global stage. "Having in mind strategic goals one can come to the conclusion that, at the level of the community bodies, it has been understood that the current economic model is very close to the moment when it will reach its limits and, if not acted in advance, the effects will be dramatic. The European Union faces many more acute challenges. Virtually all facets of integration that seemed to contain no vulnerability are questioned. At the moment of the adoption of the Maastricht Treaty, the re-start of an integration process labeled "progressive and irreversible" is celebrated and now everyone is focused on BREXIT. The completion of the Single Market was marked on January 1, 1993, and since then, programs are being developed to finalize this stage of the integration process. In this context, the following assertion sounds very suggestive "the single internal market at EU level based on the values of the rule of law and defined by the high level of competitiveness, must be completed with a new priority - the achievement of a friendly, environmentally friendly, green and fair Europe,., (Wixforth and Hofman, 2019).

Imagining a new model of development, operational and sustainable at European level, forces the members of the scientific landscape but also those of the real economy

Vol. $21 \cdot$ Special Issue No. $13 \cdot$ November 2019 
environment to take into consideration even more parameters such as: the transition from a societal logic based primarily on conformity to one in which proactive behavior in the process of reporting on the mechanisms of European integration is essential; re-aligning the demarcation lines between the functional mechanisms of the markets and the state interventionism; giving up a logic of "hegemonic arrogance" type; identifying and avoiding the pitfalls fueled by the democratic and regulatory deficits; assuming a new balance between geo-economic and geo-political competition; intelligent management of the dynamic balances existing between the supporters and opponents of the new development model, on the one hand, and between winners and losers, on the other; correctly managing the challenges related to the identity of the actors participating in the economic game; an appropriate management of the correlations between the real and the nominal criteria, between possible and desirable, between the short term and the medium and long ones.

It is becoming increasingly obvious that the elements of the regulatory and institutional framework designed to facilitate the management of fully known mechanisms and whose evolution is a linear type no longer correspond to the same purposes if the generalized state of affairs is one of discontinuity, of turbulent developments and new challenges arising from increasing the share of the tertiary and quaternary sectors of the economy. In these new circumstances it is no longer possible to treat a certain type of new generation macroeconomic and sectoral disorders with drug schemes devised many years ago. The most pressing challenge is no longer that of norms of conduct agreed consensually and applied discretionary and indisputable, but that of some rules suitable for the present and especially future problems.

The processes of economic development, as well as the times of crisis that they go through, are cyclical in nature, but their management requires strategies, mechanisms and tools that can provide solutions to unpredictable developments. Understanding in time the transition to new models of economic development can facilitate the internalization of opportunities, the most important being the possibility of coordinating actions according to the priority of the challenges; associated with the concertation of tactical means and the speed of the reactions. However, some risks should not be ignored such as: increased difficulty in estimating all effects; the impossibility of devising the most appropriate counter-strategies; the deficit in the coherence plan of the measures taken. It must be learned from certain experiences that proved negative and that the former socialist economies had, which have largely mimicked the values considered panacea of the traditional market economy, blindly believed in its capacity. to optimally allocate resources and equitably redistribute results, he has discretely applied his recipes and is now reaping the fruits of this behavior. All corporate actors will have to prove that they understood that it can no longer be consumed as before, consumers not expecting products and services but maximizing the satisfaction promised by those who offer them, that companies can no longer sell at levels that always are, coinciding with the optimum of the first degree and the decision makers regarding macroeconomic and sectoral policies will have to revive the term of economic rationality.

Another area in which there will be a major change of dominant logic in the economic landscape is that of competitiveness. Extremely complex concept on which the opinions of analysts (Siudek and Zawojska, 2014) go from putting under the sign of doubt to assuming unreservedly its valences. In the first category, exponentially is Nobel laureate Paul Krugman (1996) who based on the hypothesis that "competitiveness is a dangerous obsession" argued that "the idea that a country's economic wealth is largely determined by 
its success in global markets is a hypothesis, not necessarily a truth "adding that" in practical, empirical terms, this hypothesis is categorically wrong. This simply means that the leading nations of the world are in an important measure in economic competition, against each other or that any of their major economic problems can be attributed to the failure to compete in global markets. "At the other extreme we can place the perspective cultivated for several years at the World Economic Forum where competitiveness is defined as "the set of institutions, policies and factors that determine the level of productivity of a country", ,.. "the ability of countries to achieve sustained high rates of growth in GDP per capita, to provide high levels of prosperity to their citizens. This in turn depends on how productively a country uses available resources". Starting from the approach angle established in the great economic literature according to which " economists, in general, do not use the word competitiveness" (Krugman, 1996), a valuable Romanian specialist (Munteanu, 2019) draws attention to the fact that they are committing a big mistake when one considers that „competitiveness is at the same time productivity, and efficiency, and profitability, and effectiveness, and prosperity, and competition. The real problem is that it comes out of nowhere what distinctive features competitiveness has against the above mentioned "related" concepts (which are indiscriminately incorporated in it, as in a genuine conceptual mixture),, It has become a cliché that the rhetoric of competitiveness has been taken over with abnegation in all the major schools of economic thought, in the strategic agendas of international or regional organizations as well as in the political programs of national governments. Still the reverberations of the strategic European goal (reachable in the Lisbon Strategy) are still vivid and they envisaged the transformation of the European Union's economy into "the most competitive and dynamic economy in the world" to generate "more growth, more and better jobs".

The confusion surrounding the concept of competitiveness, the ambiguity with which it is defined, but especially its use to promote agendas labeled more and more as "occult", brings back the idea that, before moving to a new development model, it is necessary finding the most acceptable answers to some questions such as: Does the new macro and microeconomic context require replacing the established concept of comparative advantages, now considered inadequate, with the concept of competitive advantages? To what extent the sources of competitive advantages are different from the sources of comparative advantages; Does calling on one concept or another (competitiveness, productivity, economic performance, prosperity) substantially change the recommendations of economic policy? To whom should the recommendations that result from the acceptance of the concept of competitiveness be addressed? What is becoming increasingly important is what one expert (Mocearov, 2008) termed the paradigms of switching from Europe as an attenuator of globalization to Europe as an agent of globalization, and from Europe as power to Europe as market. New challenges also accrue because although a fragmented market needs a regulatory and institutional impetus to make it truly functional, however, exaggeration in either direction may threaten the existence of stabilization and redistribution functions of the state and the very idea of public goods. We will have to bend with greater determination on the subject of "inseparable opposites", in the context of this research on the inseparability between the development model and the freedom of action of the social actors placed in the logic of the functional market and of the sustainability and economic rationality. Despite the enthusiasm that was shared, at one point, by most of the schools of economic thought, leading to what has become the "great moderation", the concrete economic realities have proven that the priority orientation towards what can be

Vol. $21 \cdot$ Special Issue No. 13 • November 2019 
called "market fundamentalism", causes opportunities to become major constraints for any type of new development model.

Given the expected transition from a model of development of an economy structured in three sectors (primary, secondary and tertiary) to another that adds a fourth sector (intensive knowledge and creativity), the risk of additional "irrational exuberance" that will inherently contribute to the reconfiguration of economic cycles must be carefully considered. It has become almost a truism that the positioning of any economic actor at the level of the reconfigured regional and global economic landscape depends essentially on numerous macro and micro-economic parameters the most pressing being: economic gravity exerted towards the external environment; ability to assimilate knowledge; ability to promote the acceptable level of autonomy; the ability to manage market imperfections (with two dimensions: control over internal imperfections and fruition of external imperfections). A series of failures capitalized at European level are already emblematic at the level of the process of implementation of ambitious strategic programming documents (Agenda 2000 and Lisbon Strategy). With its focus on smart, sustainable and inclusive economic growth, the Europe 2020 Strategy was about facing a series of failures that would make the process of ensuring the right balance between cohesion and competitivity even more difficult. As pointed out by some experts (Blanke and Lopez-Carlos, 2004), the new development model at European level will have to have among its reference pillars, in particular: the creation of an information society available to all; development of a national and European space for research, development and innovation; advancing towards market uniqueness; harmonization of competition regulations; building network industries in utilities and transport; creation of integrated and efficient financial services; improving the environment for businesses; increasing social inclusion: increasing employment; the shift from focusing on knowledge memorization to focusing on cognitive skills development in education; mitigating inequalities; focusing on actions that promote the processes of sustainable development logic.

\section{The need for correlativeness and causality at the intra- and inter-sectoral level}

An initial attempt to analyze the structure of an economy in the three sectors, insisting on their specific characteristics, is found in Wolf (1955). In the analysis of the proportionality between the sectors of the economy we used variables such as: the share in the GDP; contribution to added value enhancement; weight in the process of providing jobs; generated cross-border trade flows. Using the labor force factor as a methodological parameter, Clark (1976) investigated the main differences between the primary, secondary and tertiary sectors, providing a first methodological support for the analysts who dealt with what appeared to be economically settled a phenomenon of deindustrialization" (Mukherjee and Feller, 1978; Bacon and Eltis, 1978; Blackaby, 1979) For a certain period of time, the concepts of deindustrialization and tertiarisation were treated from the point of view of an inverse correlation between them, considering that tertiarisation is both a cause and an effect of diminishing the importance of the manufacturing sector. It was assumed that the aggregate rate of productivity in the tertiary sector is lower than that of the secondary sector, which will lead to a decline in total productivity in the medium and long term. Other authors (Buera and Kaboski, 2012) have reached different conclusions, thinking that at the level of several activities included in the tertiary sector, productivity is on an upward trend, exceeding the average in the secondary sector. 
The principial and operational architecture called the Washington Consensus was based on several assumptions about how national economies should be managed and the expected behavior of economic actors. The main assumption was that the recommended development model was one in which natural and social capital could be considered abundant, while the physical one was deficient. Thus, the foundations of a defined social behavior were laid down as, as one of the analysts points out (Constanza, 2009), "humanity should not be too concerned about ecological and social externalities, assuming that they are external they are insignificant and solvable". The economic growth was expressed by the increase of gross domestic product considering that this indicator also contains the relevant information on prosperity. Although several decades have not been at the top of the public agendas, the subject of people's prosperity and the improvement of their quality of life, in the new global economic context, they become of utmost importance. It has become increasingly clear that the elements that make up the Gross Domestic Product (GDP) represent at most means by which prosperity can be achieved, not the purpose of its maximization. The distinction between the impact of real poverty on the standard of living and the income classes existing in a society will have to be fully understood. Only in this way can a new vision be reached about the concept of economics and the true role of rational economic behavior. An economy in which the Quaternary sector is becoming more and more important must be one in which more desires such as satisfaction, happiness, comfort, self-satisfaction (wellbeing) matter, and science must devote more interest to them. The design of an economy in which the tertiary and quaternary sectors are increasing, will be significantly improved, the range of component activities being diversified and their priority being a fundamentally different one. Frank (2000) underlined that, in perspective, people will be preoccupied with "spending more time with family and friends, volunteering for the communities they belong to, preserving their physical and mental health, and admitting the nature". In support of this new way of life, the quaternary sector will come more and more with the help of the knowledge and creativity it implies. Scientific researchers are forced to answer a growing range of questions, the most sensitive being: Have people considered themselves happy in the past? How happy are people today? How high is the coefficient of satisfaction felt by the citizens of different countries? How do the basic elements of the quality of life affect the development model and the relevant societal architecture?

By publishing the paper "Toward a Theory of Economic Growth", Simon Kuznets paved the way for a series of adjacent scientific contributions in which numerous epistemological and praxiological clarifications have been made regarding the fundamental transformations that take place within the sectoral structures of economies. An aggregate macroeconomic picture defined by the cited author (Kuznets, 1968) was set up, in the following way ".... it can be seen that there are significant evolutions regarding the presence in the economy of the non-agricultural sectors. The share of the extractive and processing industry in employment initially increased significantly but was subsequently reduced by increasing the share of other sectors such as transport and communications. The sectors in which the growth rates have remained constant have become those of business, professional or public services ". One can take note of the solution in the different methodological registers of the set of specific dilemmas, which has caused that the challenges of macro and mondo economic nature are dealt with the help of the specific instrumentation of the theories regarding institutionalism, development and forecast, those regarding the delimitation between the productive and non-productive sectors by appealing to the accounting of 
national accounts and those aimed at the stages of the economic development process by using the analytical tools developed within the theories regarding the economic growth.

The radiography of an increasingly rich specialized literature allows the researcher to find that it has been understood at more and more levels of the economic decision process but also that of the econometric analysis, that the national, regional and global economic reality has changed substantially. It is no longer a secret to anyone that the main sectors of a modern economy (primary, secondary, tertiary and quaternary), although they maintain a series of similarities of systemic nature, are also quite different from each other, which makes the instrumental analysis reconsider, the operational methodological package and the basic epistemological picture. In the traditional way, the specialized research focused on the factors of production, the determinants of development, the referential vectors of economic growth and the correlations and causal relationships fed by these aspects.

Under the conditions of a new societal framework, in which sustainability (economic efficiency, social responsibility and ecological resilience) is decisive, it is compulsory to rethink the course of action so that economic growth, but also efficiency and effectiveness, can be taken into consideration by looking at the magnitude and nature of the changes that take place at the level of each of the sectors as well as the contribution they can make to the aggregate prosperity and to the redefinition of the relational picture between the societal actors. Starting from this initial perception on the sectoriality of the economy, in the last decades we have witnessed the paradigm shift at the level of the modern economy picture, the analytical vectors being different which led to the configuration of another design of the economic sectors, the quaternary being detached from the tertiary one. (which now includes all services) and including activities defined by intensity in creativity results. In the new dominant logic specific to the Fourth Industrial Revolution, terms such as: smart manufacturing or mass customization (Marsh, 2012) and 3D printing or mass personalization (Yang and Zhao, 2015) become epistemologically and praxiologically relevant. The main challenges attaching to these developments mainly concern the changes that will occur in the plan of the mechanisms generating prosperity but also in the one of the productivities of the work. In addition to that, intelligent design and management of the type and level of flexibility that specialization structures will have to enable users of goods and services to participate in the various phases of the production processes. Both modern directions towards the current picture of the economy are becoming intensive in new factors of economic growth, especially in digitization, adaptability to the incentives coming from markets and connectivity between the physical and cyber spaces. What all actors operating in the new business environment need to understand is that they are required to become proactive in behavior and to show the highest level of responsibility in relation to market requirements. The times are coming when new products and services will be designed more and more frequently for a demand that does not yet exist, rather than in a latent state, and the demand for products and services that have not even been designed will be educated. Revolutionary changes will have to be made also at the level of the logistics chains, the geographical diagram of the cross-border trade exchanges but also the negotiation, contracting and business mechanisms.

This is the context in which the quaternary sector of the modern economy is steadily advancing, which not only adds to the other three traditional ones but forces them to reconfigure, by stimulating and offering them the essential vectors of modernity. It is necessary to redefine what some analysts (Gibbons et al., 1994) termed as a transition from 
a traditional landscape (generically referred to as Module 1) to an advanced one (generically referred to as Module 2) that forces radical changes in the dynamics with which new scientific challenges arise, new analytical methods and tools, but also new concrete results of the process of knowledge creation. Under the emergence of the quaternary sector of the economy, the dividing lines between the traditional scientific disciplines and between the fundamental and the applicative component of the research programs become more and more diffuse. Interdisciplinarity leaves room for transdisciplinarity, making the information flows between theory and practice absolutely necessary, but also between the providers of advanced knowledge and its beneficiaries, generating a rapid transition from the continuous search of the fundamental principles to the answers to questions that appear as the objectives become clearer. In this context, the various forms of advanced knowledge more easily cross the frontiers of the classical scientific disciplines, the human resources become more mobile, and the organization of the scientific research becomes more dedicated and generates new value.

In a recent paper Miron and Șeuleanu, (2019) emphasized that the information economy instrumentation serves to generate knowledge, to disseminate it, but also to quantify the impact that knowledge and creativity have on development processes. As the congruent processes of specialization and diversification of economies have advanced, it has become increasingly evident that the portfolio of competences necessary to make possible the operational mechanisms defining for an increasingly advanced economy has diversified, which has led to the multiplication and deepening of the correlations. between the four sectors of the economy. The type of economic actors operating at the level of the business environment is changing with increasing speed, the current methods of corporate governance are becoming obsolete, new types of natural, financial and structural factors of production are needed, but we are also witnessing the sharpening the need for new specialized and transversal competences but also of cognitive skills which exerts strong pressures on the education and training systems. For decisions made by public policy managers and executives at the company level to be some that maximize well-being, the earnings of private actors and confer corporate sustainability can no longer be circumvented by the aspirational horizons of citizens. Based on the careful reading of numerous studies that have dealt with the structure of the modern economy in the four sectors, we have reason to believe that gradually the process of allocating resources to various productive or non-productive activities is somewhat departing from the state of economic optimum, as it was. defined in the specialized literature. The information we have shows us that, due to the maintenance of some statistical asymmetries and the inadequacy of the analytical instrument at the rate at which the changes in the picture of the modern economy occur, a relatively unsustainable importance is given to the large tertiary sector (especially the financial, banking and financial services). insurance; education; legal and consulting services or administrative services), neglecting the secondary sector of the economy and almost ignoring the quaternary whose activities are rather implicitly found in the other two sectors. There is still wide debate about the classification of some of the services (either public or private) in the category of final assets or intermediate assets. An analyst of this thematic area (Kenessey, 1987) argued that "instead of rethinking the true limits of the productive sector but also those of the services sector, it is recommended that the analysis focus on the aggregate approach of the productive processes taking into account consideration of four sectors while also modernizing national accounts ". In this way, one can better calculate the contribution of these sectors to the total social product, their

Vol. $21 \cdot$ Special Issue No. $13 \cdot$ November 2019 
aggregate efficiency but also the spillover effects that appear at the level of the intersectoral growth network. The imperfections that remain at the instrumental level by which the contribution of the various economic sectors to aggregate prosperity can be quantified have made a number of areas of inefficiency appear, leaving the impression that certain sectors of the economy would have lower contributions to macro and meso-economic performances. In the case of the European Union, the quite asymmetrical development asymmetries, but also the different specialization models of the Member States, caused a series of adverse reactions to the different strategic programs adopted at European level and vulnerabilities related to the similarities of the production and export nomenclatures, which puts its mark on the desires of economic, social and territorial cohesion, competitiveness and proportionality regarding the efforts made. It is of the nature of the evidence to accentuate the risk of accentuating the macro and world-economic imbalances with very risky effects for the stability at regional and international level.

Starting from the assumption that in the Quaternary sector of the economy there is a lower level of economic efficiency, a number of analysts have credited the idea that the emergence and development of this quaternary sector of the modern economy has led to the reduction of the aggregate rate of increase of efficiency at economic level. Such conclusions can be drawn only because they operate with a methodological apparatus developed for an economy structured only in three sectors, not taking the steps required by the new economic reality. If indicators such as productivity, degree of satisfaction, prosperity, results are considered quite different in the analysis processes, what makes us appreciate that, under the new circumstances, there is no reduction in productivity or that the rate of efficiency in the tertiary and quaternary sectors would be lower than in the secondary sector. The idea that most analysts start with is that there is potential for increased efficiency in any of the four sectors of the modern economy. What should be placed first on the decision-makers' agendas is the design of new schemes for allocating production factors between the four sectors, only the optimal combination between them being the key to maximizing the expected results. Attention should also be paid to the careful selection of activities that fall into each of the sectors of the economy. We have identified a number of criticisms to the methodological schemes based on which certain activities are fully integrated in the intensive sector of creativity and knowledge, which makes some sub-activities, while strongly intensive in creativity, to be placed now in the primary and secondary sectors. It can be exemplified by activities related to genetic engineering, biotechnologies or fine-tuning chemistry, while other activities that do not generate advanced knowledge remain included in the Quaternary sector. Although current consumers are looking for the maximum level of satisfaction that the products and services purchased can provide, it is still believed that the satisfaction of the final consumer of assets generated in the Quaternary sector is still outpaced by that sustained by the assets realized in the other sectors. It cannot be omitted that the new model of development structured on four sectors is one in which the weight of repetitive activities is diminished, increasing that of the defining ones for the process of managing the intangible assets that do not have a dedicated destination and cannot be stored.

It is more than obvious that under the emergency of the Quaternary sector, the "bicycle principle" is becoming increasingly applicable, according to which the maximization of the expected effects can only be achieved at a certain level of the speed with which the economy maximizes as a whole evolves. At the level of the European Union it must be fully understood that there should be a switch from the desire for economic growth to that 
of economic and social prosperity, from an economy based on traditional resources to one based on creativity, from focusing on economic cohesion to competitivity poles. In these conditions, although it is important to maximize efficiency in each of the four sectors of the economy, it is even more important to the aggregate efficiency by eliminating the existing areas in each sector that lead to the erosion of productivity and efficiency in other sectors. This can only be achieved if the maximum level of harmony between sectors is ensured, so that efficiency gains in one sector are not made in the absence of efficiency reduction in the other sectors. The European economy faces more and more challenges and will have to be prepared to absorb ever more profound and numerous shocks, both symmetrical and asymmetrical, on the demand side but also on the supply side, both internal and external. Numerous studies have clarified the dilemma related to the existence of structural asymmetries, bringing sustainable arguments in favor of the idea that they are not based on increasing the importance of the tertiary and secondary sectors or increasing the volume of real and immaterial assets obtained in these sectors. The authors who dealt with this topic started from several hypotheses, the most frequently found in the consulted works being the one according to which the aggregate level of productivity in the tertiary and quaternary sectors is lower than that existing in the primary and secondary sectors. Kuznets (1966) himself was adept at the idea that "a lower level of elasticity of demand for food and current use and a higher one for durable goods and services" can be found. The most sensitive challenge for researchers in the field of economic science concerns the quantification of the final product realized in the Quaternary sector, in addition to the one regarding the difficulty of estimating the costs of the deepening of the specialization and of the new division of labor. When the very dynamic sectors of the modern economy do not find the specialized econometric apparatus ready, the correct capture of the volume of resources allocated has to suffer. However, advancing the Quaternary sector of the economy is both inevitable and beneficial. Despite this certainty, adapting to the new challenges is not easy, the possibility of feeding areas of inefficiency being very high. Despite the progress made in recent years, the issue of structural analysis of the economy needs to be deepened further. Historical reality has shown that the transition from any traditional sector to a more advanced one was difficult. This situation is also encountered in the case of the transition from the predominance of the tertiary sector to the quaternary sector.

\section{In the 21st century the fundamental transformations of the models of macroeconomic and business development become acute}

In the new economic circumstances, terms such as: information-based society (information technology modifies the societal picture); the knowledge-based society (knowledge becomes a very important vector of development); a society based on lifelong learning (knowledge becomes the main enhancing factor of productivity and competitiveness); expert society (significant growth of the role of high qualification and advanced cognitive skills; network society (one in which the intellectual capital, especially the relational one) is important; postindustrial society (one in which the tertiary and quaternary sectors are prevalent); post-modern society (one of the plurality of values and the manifestation of individualism) or society of uncertainty, have advanced in the analytical landscape. At the level of the European Union, the most important sector is the tertiary sector (of services) holding $74.7 \%$ of GDP, followed by the processing sector with only $23.8 \%$ and, at a great 
distance from the agricultural one with only $1.5 \%$. The European model of development that had for many decades as the main driving forces for exports, private consumption and investments was exposed to increasingly pressing challenges generated by the changes that have occurred in recent years at the international level of competitiveness, consumption habits but and the direction and structure of international capital flows. The latest developments in the evolution of financial and capital markets, trade disputes (especially between the US and China), deepening uncertainty and slowing the pace of development of the various manufacturing sectors need to be considered more and more carefully. regions of the planet. We find in some specialized studies (Balcerowitz et al., 2013) some vulnerabilities of the European model of development, the most acute being: the quite high taxation that redirects the financial resources from the business sector to the public one; the slowness with which the public authorities respond to the macro and world economic challenges and make the prioritization decisions at the level of the resource allocation process; the asymmetry that is maintained between the measures of consolidation of the budgetary balances and those of the reform of the picture related to the supply part of the economy; the slowdown with which progress has been made towards completing the single market and the maturing of the monetary union which has affected the national programs of structural reform; the high discontinuity in the economic growth plan (the higher frequency with which the periods of economic slowdown were manifested compared to those of economic growth); the high coefficient of mistrust in the soundness and fairness of the reform programs, which led to the high reluctance of investors; the turbulent fiscal discipline which had negative effects on the internal saving rate and the inflow of capital from outside the EU; the major development gaps between Member States, on the east-west and north-south axes, to which the intra-national ones are added; the structural asymmetries amplified by the crisis started in 2008, which are far from diminished and will exert significant pressure on any attempt to reconfigure a new development model.

In the future, the biggest challenge for decision makers will be the one related to the identification and intelligent and sustainable management of the dynamic balance between specialization and diversification. An economy composed of four or even five large sectors, further amplifies this challenge and makes the fate of those who develop public policies but also those who implement business models who wish to be successful, even more difficult.

Particularly after the magnitude of the global economic and financial crisis has subsided, certain sectors of the European economy (pharmaceuticals, transport equipment, high technology intensive products or other manufactured products) have resumed their upward trend, rapidly recovering the losses recorded over the course of the year. crisis. The production of high technological intensive goods and those of consumer goods register significantly higher rates compared to those producing capital goods, mainly due to the different elasticity of demand but also to the sensitivity in relation to the stage in which the business cycle is.

However, the macroeconomic picture is very different across countries, with the share of the tertiary sector being very high in countries such as Great Britain, Luxembourg, Greece, Spain, or Cyprus, while in Central and Eastern Europe but also in Germany, France. or Sweden, the share of manufacturing sectors remains quite high. Larger economies are more diversified than the EU average, the level of specialization being somewhat lower, which is the opposite in smaller economies. The detailed analysis gives us interesting conclusions regarding the specialization of the EU member states, as it is possible to speak of a 
specialization in the case of certain states. The different level of diversification and specialization of economies leads to a differentiated demand for human capital which will amplify the movement of labor within the EU, the most favored categories of workers being those with a higher degree of qualification. The process of specialization at the level of the European economy will rapidly advance towards increasing the importance of high technology intensive sectors, value added generators, registered in the global value chains and which require new cognitive skills and abilities. The strongest steps in this direction have been taken by Denmark, Finland and Sweden, which are noted by a high index of the presence of high-intensity sectors in state-of-the-art technologies.

Although some steps have been taken in front of the countries in the less developed areas of the European Union, developing the sectors of computers, automobiles or electrical and electronic equipment, there is still a dependence on traditional productions (textiles and clothing), leather products, food, beverages, wood products, cellulose and paper or office equipment). The changes of the techno-industrial paradigm at the level of the processes of macroeconomic specialization will depend in the following years on a panel of internal and external factors, the most important ones being considered: the endowment with production factors; the level of development and diversification of the economy; investment policies; demand developments; the quality of education and training processes; research, development and innovation potential; the level of openness to the external environment; legal and institutional framework; the quality of the business environment. The conclusion that can be drawn is that we cannot identify an authentic European model of specialization and diversification, the models remaining national priority even though, as the European economic governance process advances, the uniformity coefficient at the level of these processes increases. The consulted statistical data allow us to come to the conclusion that the least developed countries in the EU have made remarkable progress in diversifying the specialization structures in the secondary sector of the economy, while the advanced ones have continued to focus on the tertiary and quaternary sectors of their economies. . The experiences in this regard of countries such as Belgium, Denmark, Finland, France, Italy, the Netherlands, Portugal, the United Kingdom, or Spain are very inspiring.

The perspectives on the change of techno-industrial paradigm are kept quite different, both for the experts from the academic environment and for the decision makers from the institutional, national, regional or international level. One of the analysts (Pink, 2005) is adept at the idea that "'true paradigm shifts represent drastic, sometimes uncomfortable change. It is not surprising, therefore, that these events can be met with resistance as organizational leaders step outside their comfort zones`. Given the complexity of the phenomena that take place, we can suggest that the main attention be paid to variables such as: changes that take place in the plane of the aspirations of individuals, inequalities of all kinds or the sustainability of earnings. It is becoming increasingly obvious that identifying the weaknesses of the organization, relying on known competitive strengths and anticipating opportunities and risks is no longer sufficient to go further in understanding their rationale for being the factorial determinants of training effects. It resonates quite politely the recommendations of one of the authors (Pink, 2005), who argues that "it will no longer be enough to create products, services, experiences, or lifestyles that are only functional. Today, it becomes economically vital and rewarding from individually, to create something that is both wonderful, exciting and emotionally exciting." Although there are still some analysts who argue that we are in the last phase of the third industrial revolution, after Klaus Schwab labeled the current state of the modern economy as one in the first 
phase of the fourth industrial revolution, we understand more clearly that we are living in times when individuals have to choose between the digital sphere and offline reality using interconnected networks. and highly technologically intensive to set up and manage their own lives. In such a dynamic picture I move has, concepts like cyber-physical systems, the Internet of things or the Internet of systems are becoming more and more available. These new realities profoundly influence the entire design of the economy, determining the magnitude and speed with which the referential principles of the functioning of the company must be discovered, new technological systems must be imagined, new business models configured. In close connection with these transformations, it becomes compulsory to rethink the stock of knowledge, skills and cognitive abilities held by those who compose what is called intellectual capital, the talent and the attitude becoming preconditions of the new competitiveness. At the center of the economic picture composed of four or even five sectors must be placed: the proactive attitude towards the new opportunities, which must be identified quickly and correctly, the generation of maximum synergy at the level of value chains, the operation with increasingly sophisticated equipment but also with an increasing degree. autonomy, regulating the mode of action and managing a growing number of robots and additive manufacturing (3D printing).

The challenges that must be faced are not just some other type, but are based on other societal paradigms, are driven by increasingly complex and difficult to anticipate factors, they contain increased coefficients of uncertainty, which makes accumulating an increased degree of contagion and to become mandatory new portfolios of means with which the challenges of the nature of time and space can be better managed. The analysis we carried out revealed a big change in the societal level, namely from the one defined by disciplinarity (based on specialists) to that characterized by inter and trans-disciplinarity (reliance on facilitators, or integrators). The new economy requires individuals who, in addition to the ability to use the accumulated experience, also have the ability to capture the correlation between phenomena and processes and to extract added value from it. The challenges that require urgent identification of feasible and applicable solutions under conditions of economic rationality, social responsibility and ecological resilience become: climate developments and the relative scarcity of energy resources; the transition from human resources to intellectual capital; combating inequalities of all kinds; efficient use of financial capital flows; the manageable correlation between infrastructure and infrastructure; ensuring food security; the correct relationship between unilateralism, regionalism and multilateralism on a commercial level; providing global public goods and combating "public ills" that have become global.

As we have pointed out (Miron and Șeuleanu, 2019), the new model applicable at European level cannot be imagined without relying on analytical and methodological vectors such as: dynamic and multidimensional working climates change; increasing the share and societal relevance of the middle class in emerging economies; worrying climate change; the increasing constraints exercised by the balance of natural resources; geopolitical volatility in dynamic amplification; the increasing concern of the consumers of the planet regarding the ethical aspects and those related to respecting privacy; The "graying" of our planet; strong asymmetrical demographic growth in various regions of the globe; the impressive dynamics of the urbanization process. We find that it is advancing steadily from international relations to global governance, from bilateral to triangular or plurilateral diplomacy, from the inventory of problems to offering an alternative. The new societal realities generated by genetic engineering, artificial intelligence, robotics, 
nanotechnologies, biotechnologies, or 3D technologies, change the geopolitical and geoeconomic landscape, force the rethinking of the regulatory and institutional framework, change attitudes and behaviors, require other kinds of resources and make it vital intergenerational balance. The transformations to which all four sectors of the economy are exposed lead to significant job-creation effects, which puts education systems under unprecedented pressure, provided they are not fully prepared to face the challenges. The statistical data consulted allowed us to find that there have already been significant changes in the plan of labor productivity and the deepening of the asymmetries between the competences required by the new economy and the qualifications offered by the education and training systems.

\section{The Romanian economy at the moment of paradigm changes in the economic sectoriality plan}

Increasing the importance of the Quaternary sector of the modern economy, a powerful one intensive in information, knowledge and creativity, diversifies the dilemmas, narrows the range of existing solutions and forces to change the dominant social logic. We can only agree with those held by some analysts (Hagel, Brown and Davison, 2010) that although "solving problems and developing strategies remains the central pillar of any business" ... "as changes occur of the Internet generated background and the exponential evolution of artificial intelligence ... the traditional determinants of top-down philosophy are no longer maintained. " The urgency of the company has already appeared on the horizon of concerted efforts to adapt to several categories of change although most of the corporate actors are far from ready. The European reality shows that almost all the governments have failed to operationalize those strategies and public policies that put at their center the stimulation of the processes of generating advanced knowledge, to make known throughout the society the unique aspects attached to the new technologies and to reposition the processes that contribute to the maximum processes. welfare in the logic of the spiral quadruple, one in which public authorities, actors in the business environment, experts in the university environment and civil society representatives participate synergistically. At the level of a development model in which four major sectors coexist, the focus is on the speed with which the adaptation is made to change, on exponentiality and not on predictable and linear iterativity. The steps to identify the most appropriate development model are not easy to undertake, they contain numerous pitfalls and involve radical transformations at the level of each of the sectors of the economy equally, targeting the productive systems, those in the area of leadership or governance. The process of deepening income inequalities, accumulating dissatisfaction with the effects of economic crisis phenomena and associated austerity programs or upsetting the human resources market, which is becoming increasingly segmented between the "few skills / needs" approach, must be stopped. little money "and" multiple specializations / more money ". It is no longer the domain of the future to state the fact that the connectivity between the employment dynamics determined by the stock of skills available to the employer and the sustainability of his place of work changes. Statistical data support the conclusion that we already have a human resources market where demand for those with a high level of qualification is increasing exponentially, while a significant reduction in demand for people with a medium level of qualification. For these reasons, the development models from which we expect a greater prosperity will have to be seriously reconfigured, these being

Vol. $21 \cdot$ Special Issue No. $13 \cdot$ November 2019 
some in which the ethical aspects become relevant. The new drivers of success will have to be treated with greater attention at all levels of the corporate landscape - documents of international and regional organizations, public strategies and policies, entrepreneurship schemes or business models of companies, programs and projects of civil society actors. The evolutions of the last years justify us to affirm that there has already been a decoupling of the standard philosophy in the development plan from its traditional version, focused mainly on ensuring the highest profits for investors, moving steadily towards a development model. which puts at its core the social component, the satisfaction of the individual, the creation of value for sociality, civility and participation. The pillars of resistance of the new development model become the preservation of the natural balances, the energy efficiency, the economics in the plan of the use of the non-renewable resources, the relation cost-efficiency, the sustainability and the good management. To the aforementioned pillars we can add: the involvement of the individual; transparency; taking into account the messages received from the civil society; resource efficiency; preservation of the environment and anticipatory treatment of ecological challenges.

In the equation of paradigm shift at the development model level, variables such as mass production, centralized and top-down production systems, resource-intensive economies of scale, financial markets that have led to dangerous loops, evolutions that become essential they take place in the primary and secondary sectors. The member states of the European Union must participate in substantiating the answer to the question - what can the grouping do better for third parties so that they are no longer enemies but become successful partners? This objective becomes vital because it has been fully demonstrated that events that occur outside the European economic grouping can have a significant impact on the macroeconomic and sectoral policies developed and implemented. It must be quickly and correctly understood that existing structures, designed to manage opportunities and threats, are not prepared to perform their standard functions, the new purpose which is not adjusted to their diversity, scope and nature. The identification of the forms of manifestation of the incongruity does not solve the existing problems, at the most saying very little about the nature of the asymmetries but not offering effective ways of action. For these reasons, it becomes imperative to configure a new format of the development model that is compatible with the new challenges and contains innovations at all levels. At the level of public authorities in the Member States of the European Union, it should be understood that a model of economic development is needed to have the levers with which the following transitions can be managed simultaneously: from the push to the pull (from the pumping of new structures and assets to the attracting resources and consumption behaviors); from consumption to creation (from passive consumption to the active creation of new ones); from assets to facilities (from accumulation and storage of knowledge to sharing and dissemination of knowledge); from a linear perspective to a multidimensional one (from independent and predictable systems to some interdependent and adaptable ones); from the rarity to the abundance of the production factors (from a small set of alternatives to renewable resources); from universality to uniqueness.

During our research we checked the level at which the company commandments presented above are on the first places of the agendas of public decision-makers and private actors. It was vital that the new type challenges and the increasingly pressing threats coming from the external environment as well as the competitive advantages but also the defining vulnerabilities for the Romanian economy should be the subject of feverish debates at the level of the public institutions, of the experts in the academic environment, to represent 
topics preferred by public debate and it is within the scope of every citizen's concerns. We wanted to see at what level the Romanian experts are integrated in the major European and international networks established in the field of advanced research, contribute to the global dialogue of innovative ideas with raised problems and feasible solutions and compare their scientific results with those of other experts from other countries. of the world. Although some signals can be identified that things have begun to move in Romania, the result of the radiography made is an unsatisfactory one, showing apathy, non-involvement, location on the edge of the deliberative picture, inconsistency and modest contributions in the plan of generating debate topics and solutions to the big ones. problems. At the last meetings of the Davos Forum, the Romanian presence, at any of the levels, is almost non-existent, a result that is registered and in the case of other such exercises of economic type of new type. The Romanian experts are present in a very small number in the research teams that have won projects financed from the international and European programs, as there are no cases in which the researchers in our country are coordinators of these projects. The Romanian universities are in very dissatisfied positions in the international rankings, the 2019 version of the World University Rankings showing that only 3 Romanian universities are in the first 1000 and quite few around this threshold. The relevant actors in the Romanian business environment are concerned with survival rather than European or international consecration and confirmation and are not found in the arena of the large economic forums that are currently organized. The civil society is strongly fragmented, it is concerned with multiple topics but, most of the time, marginal, lacking the material, financial, organizational and human resources that allow it to tackle the challenges described in our article. There is still a long way to go until the Romanian interest groups will fully understand that the new challenges are of strategic type, not short term-tactical, which makes the solutions imagined to meet them be of the same nature and scope. The coagulation of all the issues that the Romanian society has available can lead to the responsible approach of all the effects of the paradigm changes that we referred to previously, identifying viable solutions to each of the new challenges.

One of the most vulnerable aspects of reporting the Romanian economy to the increasingly turbulent external environment is that of placing in the supply chain equation. One cannot imagine an efficient presence at the level of the international trade picture without the correct positioning at the level of the production networks and the regional and global logistics chains. Under the conditions of a new development model, one characteristic for an economy structured in four major sectors, the welfare-generating processes will be located where the necessary material and financial resources and the stocks of competences are available, these being available at the costs and the quality that generates more of competitiveness. The economic reality in Romania shows that, under the conditions in which we witness the highest degree of fragmentation of production, a phenomenon that offers concrete prospects for economic growth, technological development and job creation, there are numerous dysfunctions at the level of the reaction mechanisms to challenges.

The participation of companies with Romanian capital, almost all small and medium sized, in the global production networks becomes vital for equipping them with advanced technology, modern management methods, for exposure to foreign competition and for obtaining concrete improvements in labor productivity. In order for these expectations to materialize, in addition to embracing leadership values by private sector decision-makers, it is also necessary to develop and successfully implement public policies that will contribute 
to attracting intangible assets from abroad, making cross-border trade possible. becomes the main vector of the process of generating prosperity. The analysis of the best practices in this field shows that participation in global logistics chains generates valuable positive externalities that can materialize in: more jobs, better paid and more stable, pluses in the field of technological intensity, accumulation of high managerial expertise, more favorable placement on the similarity scale within European production and export nomenclatures. Although in the international rankings aimed at competitiveness, the most important positions belong to the big corporations, on the path of the optimization of the productive processes, the technological modernization, the easier access to foreign direct investments to the promptness in the delivery of the products and services, the quality and the services after the sale, it can succeed. The main challenge for the operational actors in the Romanian business environment is not how to participate in the global logistics chains but rather how to maximize the profits that can be obtained from this participation. A complex mix of measures must be effectively managed to include promoting policies to attract as many foreign investors as possible; enhancing the efficiency of the offer by improving the business climate; the modernization of the infrastructure and the induction of professional excellence in the educational system. We should also recognize the importance of creative culture and economy and support the development of national programs to stimulate them and to reposition them as vehicles of economic and social transformation. Developing and implementing policies targeting the creative economy does not only respond to economic needs but also to special needs of communities such as education, cultural identity, social inclusion, protection of endowment with natural resources and their integration into local, regional and global markets. The cultural and creative industries increase the competitive advantages of the states on the way of consecrating innovative products, the emergence and consecration of some brands and improving the external image of the countries that encourage them.

\section{Conclusions}

In this paper, the most pressing paradigm shifts related to the new development model demanded by the increasing importance of the quaternary sector of the modern economy, highly intensive in knowledge and creativity, were identified, testing the level at which the economy of the member states of the European Union is prepared. to take opportunities and to avoid threats. Due to the complexity of their challenges and their cross-disciplinary nature, the phenomenological analysis allowed the capture and explanation of the most relevant correlations between methodological variables and parameters, as well as the complex causal relationships configured over time and subjected to particular pressures under the ever-increasing volatility conditions of the traditional model of development, operational in the member countries of the European Union but also of the turbulence that has accentuated at the level of the European business environment.

We cannot talk about an authentic European model of specialization and diversification, the models remaining national priorities even though, as the European economic governance process advances, the uniformity coefficient at the level of those processes increases. This state of affairs is accentuated by the fact that the European decision-makers have not found sufficient arguments to decide to switch from a development model that has at its center the desire for economic, social and territorial cohesion to one that focuses primarily on maximizing the external competitiveness of the economy. integrationist grouping. 
The challenges that must be faced are not just some other type, but are based on other societal paradigms, are driven by increasingly complex and difficult to anticipate factors, they contain increased coefficients of uncertainty, which makes accumulating a increased degree of contagion and to become mandatory new portfolios of means with which the challenges of the nature of time and space can be better managed.

Although some signals can be identified that things have begun to move in Romania, the result of the analysis made is still an unsatisfactory one, showing apathy, non-involvement by the main players of the deliberative picture, leading to inconsistency and modest contributions in the plan of sparkling debate topics and solutions to the big problems.

\section{References}

Bacon, R. and Eltis, W., 1978. The Underlying Economic Theory: The Implications for Inflation, Employment and Growth of a Fall in the Share of Output that is Marketed. In: R. Bacon (ed.). Britain's Economic Problem: Too Few Producers. London: Palgrave Macmillan. pp.165-206.

Balcerowitz, L., Rzonca, A., Kalina, L. and Łaszek, A., 2013. Economic growth in the European Union. Bruxelles: The Lisbon Council asbl.

Blackaby, F.T. 1979. Deindustrialization. vol.2. London: Heinemann Educational Publisher.

Blanke, J. and Lopez-Carlos, A., 2004. The Lisbon Review 2004: An assessment of Policies and Reforms in Europe. Geneva: World Economic Forum.

Buera, F.G. and Kaboski, J., 2012. The Rise of the Service Economy. The American Economic Review, 102(6), pp.2540-2569.

Clark, C., 1957. Conditions of Economic Progress. London: Macmillan.

Constanza, R. 2009. A New Development Model for a 'Full' World. Development, 52(3), pp.369-376.

Frank, E., 2000. Rural Livelihoods and Diversity in Developing Countries. New York: Oxford University Press.

Gibbons, M., Limoges, C., Novotny, H., Schwartzman, S., Scott, P. and Trow, M., 1994. The New Production of Knowledge. Thousand Oaks: SAGE Publication.

Hagel, J., Brown, J.S. and Davison, L., 2010. Power of pull: how small moves, smartly made, can set big things in motion. New York: Basic Books.

Hagel, J., Brown, J.S. and Davison, L., 2010. Thoughts on The Power of Pull. The Cook Report on Internet Protocol, 19(4), pp.1-40.

Harmaakorpi, V., Haikonent, A. and Kauranen, I., 2003. The Shift of Techno-Economic Paradigm and Its Effects on Regional Disparities. [online] Available at: <https://www.researchgate.net/publication/23730801_The_Shift_of_Techno-

Economic_Paradigm_and_Its_Effects_on_Regional_Disparities> [Accessed 21 September 2019].

Kenessey, Z., 1987. The primary, secondary, tertiary and quaternary sectors of the economy. The Review of Income and Wealth, 33(4), pp.359-385. 
Krugman, P., 1996. Making Sense of the Competitiveness Debate. Oxford Review of Economic Policy, 12(3), pp.17-25.

Kuznets, S., 1966. Modern Economic Growth, Rate, Structure and Speed. New Haven: Yale University Press.

Kuznets, S., 1968. Economic Growth and Structure. New York: W.W. Norton.

List, F., 1841. The National System of Political Economy. London: Longmans, Green and Co.

Marsh, P., 2012. The new industrial revolution: consumers, globalization and the end of mass production. New Haven: Yale University Press.

Miron, D. and Şeuleanu, D., 2019. The analysis of the most pressing challenges related to the transition from the development models specific to an economy in which the secondary and tertiary sectors prevailes, to those economy in which the quaternary sector emerges. In: Proceedings of BASIQ International Conference on New Trends in Sustainable Business and Consumption Proceedings. BASIQ International Conference, 30 May -1 June 2019, Bari, Italy. pp.367-374.

Mocearov, A., 2008. Competitivitatea economică- condiție primordială a a integrării României în Uniune Europeană. Ph.D. Thesis. Bucharest University of Economics Studies.

Mukherjee, S. and Feller, C., 1978. Restructuring of industrial economies and trade with developing countries. Delhi: Concept Publishing Company.

Munteanu, C., 2019. Some Thoughts on the "Global Competitiveness" Beyond the glamour of Davos. The Market for Ideas, 18[online] Available at: <http://www.themarketforideas.com/some-thoughts-on-the-global-competitivenessbeyond-the-glamour-of-davos-a316/> [Accessed 21 September 2019].

Pink, D. 2005. A whole new mind: Moving from the Information Age to the Conceptual Age. New York: Riverhead Hardcover.

Rodrick, D., 2019. The Trilema. Harvard Magazine. [online] Available at: <https://www.harvardmagazine.com/2019/07/rodrik-trilemma-trade-globalization> [Accessed 21 September 2019].

Siudek, T. and Zawojska, A., 2014. Competitiveness in the Economic Concepts, Theories and Empirical Research. Oeconomia 13(1), pp.91-108.

Wixforth, S. and Hofman, R., 2019. Thinking climate and social policies as one. [online] Available at: <https://www.socialeurope.eu/thinking-climate-and-social-policies-asone> [Accessed 21 September 2019].

Wolf, M., 1955. The concept of economic sectors. The Quarterly Journal of Economics, 69(3), pp.402-420.

Yang, S. and Zhao, Y.F., 2015. Additive manufacturing-enabled design theory and methodology: a critical review. International Journal of Advanced Manufacturing Technology, 80(1-4), pp.327-342. 